This is a self-archived - parallel published version of this article in the publication archive of the University of Vaasa. It might differ from the original.

\title{
On industry momentum strategies
}

Author(s): Grobys, Klaus; Kolari, James

Title: $\quad$ On industry momentum strategies

Year: $\quad 2019$

Version: Accepted manuscript

Copyright (c) 2019 The Southern Finance Association and the Southwestern Finance Association. This is the pre-peer reviewed version of the following article: Grobys, K. \& Kolari, J. (2019). On industry momentum strategies. Journal of Financial Research 43(1), 95-119., which has been published in final form at https://doi.org/10.1111/jfir.12205. This article may be used for noncommercial purposes in accordance with Wiley Terms and Conditions for Use of Self-Archived Versions.

Please cite the original version:

Grobys, K. \& Kolari, J. (2019). On industry momentum strategies. Journal of Financial Research 43(1), 95-119.

https://doi.org/10.1111/jfir.12205 


\title{
The Journal of Financial Research
}

\section{ON INDUSTRY MOMENTUM STRATEGIES}

\author{
Klaus Grobys \\ University of Vaasa \\ James Kolari (iD \\ Texas A\&M University
}

\begin{abstract}
In this article, we investigate industry momentum strategies. We find that industry portfolios that outperformed in the previous month generate on average significantly higher returns in the holding period than those that underperformed. Plain and risk-managed strategies using this short-run industry momentum are not subject to optionality effects. Also, the tail risks of these strategies are uncorrelated with traditional industry momentum strategies. The spread associated with the risk-managed strategy both meets necessary conditions as a risk factor and is significantly priced in the cross-section of U.S. industry portfolios.
\end{abstract}

JEL Classification: G12, G14

\section{Introduction}

Empirical asset pricing research has largely focused on exploring cross-sectional patterns in stock returns. Because of the failure of the capital asset pricing model (CAPM) of Treynor (1961, 1962), Sharpe (1964), Lintner (1965), and Mossin (1966) in cross-sectional tests, Fama and French $(1992,1993)$ proposed their now-famous three-factor model with market, size, and value factors. Subsequently, researchers have advanced a growing list of factors and asset pricing models. For example, Carhart (1997) includes Jegadeesh and Titman's (1993) momentum portfolio as a fourth portfolio-based risk factor to the threefactor model. Novy-Marx (2013) suggests a four-factor model containing market, value, profitability, and momentum. Benchmarking against Carhart's four-factor model, he argues that his new model better explains more than a dozen cross-sectional asset pricing anomalies. Hou, Xue, and Zhang (2015) posit a new factor model consisting of market, size, investment, and return on equity factors that improve on Carhart's model. Relatedly, Fama and French $(2015,2017)$ update their earlier research by offering a five-factor model that adds investment and profitability factors to their earlier three-factor model. Fama and French (2018) augment this model with the momentum factor to form a six-factor model.

We are grateful for the comments received from the participants of the INFINITI Conference 2017 in Valencia (Spain). We also appreciate the useful comments from the participants at the Accounting and Finance seminar 2016 at the University of Vaasa. In particular, we thank Ali Anari, Julian Gaspar, Seppo Pynnönen, and Wei Liu. We also thank an anonymous reviewer for helpful comments. 
In general, as models have become more refined and complex, the ability to crosssectionally price stock returns has gradually improved.

Particularly relevant to our article, a major gap in the asset pricing literature exists with respect to industry portfolios. Lewellen, Nagel, and Shanken (2010) investigate the usefulness of standard risk factors, such as the size and value factors, for pricing U.S. industry portfolios. Unfortunately, "adding industry portfolios dramatically changes the performance of the models, in terms of slope estimates, cross-sectional $R^{2} \mathrm{~s}$, and $T$ statistics. Compared to regressions with only size-B/M (book-to-market equity) portfolios, the slopes estimated using all 55 (industry) portfolios are almost always closer to zero and the crosssectional $R^{2}$ s drop substantially" (Lewellen, Nagel, and Shanken 2010, p. 189). Given that standard risk factors do not explain the cross-section of industry returns, the question arises: which factors span the returns of industry portfolios? To our knowledge, no study addresses this question.

Filling this gap in the literature, we investigate the asset pricing implications of different industry momentum strategies. Following standard practice, we sort U.S. industry portfolios into quintiles. The first group comprises industries that have the lowest returns in the previous month, and the fifth group comprises industries with the highest returns in the previous month. A zero-cost strategy is constructed that is long (short) the fifth (first) portfolio group. Using a correlation analysis, this strategy is compared to traditional industry momentum strategies. Further analyses examine whether the industry momentum strategies can be explained by the Fama and French $(2015,2017)$ five-factor model. Motivated by recent literature on risk-managed momentum, we also explore risk-managed industry momentum strategies and their associated tail risks by means of optionality regressions. Finally, we employ stochastic discount factor model analysis to determine the usefulness of the proposed strategies for pricing the cross-section of U.S. industry portfolio returns. Split-subsample tests are employed to check the robustness of the results. Moreover, a recently developed statistical approach is employed to investigate whether the strategy satisfies theoretically motivated necessary conditions to qualify as a risk factor.

This article contributes to the literature in several important ways. First, we investigate the correlation between different industry momentum strategies. In this regard, Grobys, Ruotsalainen, and Äijö (2018) find that industry momentum is uncorrelated with risk factors in Fama and French's (2015) five-factor model. Grobys (2018) proposes a 52-week high industry momentum strategy with similar results. Also, Grundy and Martin (2001) argue that the industry momentum strategy can largely be explained by the first-order autocorrelation of industry returns. Second, we extend Grobys, Ruotsalainen, and Äijö (2018) and Grobys (2018) by employing Moreira and Muir's (2017) risk-managing approach to the proposed zero-cost portfolio based on first-order autocorrelation. Unlike previous studies, we explore whether the zero-cost portfolio based on short-run industry momentum or its risk-managed counterpart are subject to Daniel and Moskowitz's (2016) optionality effects. In doing so, we extend Moskowitz and Grinblatt (1999), who also document the profitability of short-run momentum. Specifically, Moskowitz and Grinblatt explore microstructure effects of various industry momentum strategies, whereas we analyze, among others, conditional correlations in terms of tail risks and potential optionality effects as well as asset pricing implications of different industry momentum strategies. Third, and last, we extend Fama and French's (2018) study by comparing different industry momentum 
portfolios for pricing U.S. industry portfolios, as opposed to equity portfolios based on firm and other characteristics. We employ Charoenrook and Conrad's (2008) methodology to identify portfolio-based risk factors in U.S. industry portfolios.

A major finding is that industry portfolios overperforming in the previous month subsequently generate on average significantly higher returns than those underperforming in the previous month. This finding supports that of Moskowitz and Grinblatt (1999), who similarly document the existence of short-run industry momentum effects. The economic magnitude of the payoff differential between the long and short legs is economically large and comparable with traditional industry momentum strategies. However, the correlations between this proposed strategy and traditional industry momentum strategies are low, which is further supported by principal component analysis. Further analyses reveal that risk managing the zero-cost strategy in the spirit of Moreira and Muir (2017) adds value and substantially increases the Sharpe ratio. This finding supports that of Grobys, Ruotsalainen, and Äijö (2018) and Grobys (2018), who similarly document higher Sharpe ratios for risk-managed industry momentum strategies. In this regard, our risk-adjusted, risk-managed strategy generates between 33 and 36 basis points per month, which exceeds the risk-adjusted payoffs from Grobys's (2018) proposed strategy. Payoffs are statistically significant at any level. Moreover, the tail risks of these strategies are uncorrelated with traditional industry momentum strategies, and plain and risk-managed short-run industry momentum strategies are not subject to Daniel and Moskowitz's (2016) optionality effects. Spreads for the proposed risk-managed, short-run industry momentum strategy meet necessary conditions derived by Charoenrook and Conrad (2008) for qualifying as a risk factor. Consistent with this finding, based on Hansen's (1982) generalized method of moments (GMM) methodology, estimated stochastic discount factor models provide evidence that the proposed risk-managed industry momentum strategy is significantly priced in the cross-section of U.S. industry portfolios. By contrast, traditional industry momentum is not priced for these portfolios.

\section{Literature Review}

Following seminal work by Jegadeesh and Titman (1993) on momentum profits, Moskowitz and Grinblatt (1999) investigate the returns from a strategy of buying firms in winner industries and shorting firms in loser industries. Their results indicate that the profitability of individual stock price momentum strategies is explained by industry momentum for the most part. Thus, stock price momentum effects are mainly driven by industry factors. However, Grundy and Martin (2001) argue that for strategies using a one-month interval between the six-month formation period and the investment month, value-weighted industry strategies do not produce momentum profits. Instead, the profitability of an industry momentum strategy is correlated with the month immediately after the formation period.

Pan, Liano, and Huang (2004) attempt to link the sources of momentum profits to industry stock price movements by decomposing profits into three components. They find that the industry momentum effect is primarily due to return own-autocorrelations. Using Datastream industry classifications, Swinkels (2002) corroborates Moskowitz and Grinblatt's 
(1999) U.S. momentum findings for European stocks. Also, Su (2011) documents significant abnormal profits for industry momentum strategies in Chinese stock markets. ${ }^{1}$

In recent papers, Plessis and Hallerbach (2016) and Grobys, Ruotsalainen, and Äijö (2018) examine the profitability of risk-managed momentum payoffs using U.S. industry portfolios. They employ risk-managed approaches by Barroso and Santa-Clara (2015) and Moreira and Muir (2017), who suggest the use of realized volatilities as a scaling factor to increase the dollar amount invested in industry momentum when forecast volatility is beneath the target level of volatility, and to decrease the dollar amount invested in the strategy otherwise. Both papers find that risk-managed U.S. industry momentum adds value in terms of higher Sharpe ratios.

Another recent paper investigating cross-sectional patterns in U.S. industry portfolios by Grobys (2018) uses George and Hwang's (2004) 52-week high momentum strategy. The results indicate that this strategy generates statistically significant payoffs that are uncorrelated with risk factors in the Fama and French (1993) three-factor model. Also, this strategy is statistically orthogonal to Moskowitz and Grinblatt's (1999) standard U.S. industry momentum strategy. Applying a similar risk-managing approach as proposed by Barroso and Santa-Clara (2015), and controlling for the spread of the plain 52-week high industry momentum strategy, on average 25 basis points higher risk-adjusted returns were earned.

Plessis and Hallerbach (2016), Grobys, Ruotsalainen, and Äijö (2018), and Grobys (2018) argue that the respective investment strategies implemented using U.S. industries are significantly correlated with the market factor (i.e., CRSP [Compustat and Center for Research in Security Prices] index excess returns) but lack correlations with other factors in the Fama and French (1993) three-factor model. Hence, their findings implicitly support Lewellen, Nagel, and Shanken (2010), who observe that the factor structure of U.S. industry portfolios is different from equity portfolios sorted by characteristics such as size and book-to-market ratios.

This study contributes to the growing literature on exploring cross-sectional patterns in industry portfolios by examining short-run industry momentum. We explore whether a risk-managed approach diminishes potential optionality effects. Also, we evaluate the potential asset pricing implications of portfolio-based risk factor candidates for the U.S. industry universe.

\section{Methodology}

\section{Data}

A total of 48 U.S. industry portfolios are downloaded from Kenneth French's website (http://mba.tuck.dartmouth.edu/pages/faculty/ken.french/Data_Library/det_48_ind_ port.html). Value-weighted return data series are employed on a daily and monthly basis.

\footnotetext{
${ }^{1}$ Other papers that confirm Moskowitz and Grinblatt (1999) are Chordia and Shivakumar (2002), Lewellen (2002), and Xiuqing and Giannikos (2010).
} 
Also, monthly data series for Fama and French's (2015) five-factor model are downloaded. The sample period is from July 1926 to February 2018.

\section{Portfolio Sorts}

First, we compound returns from month $t-1(J=1)$ until $t(L=0)$ and then hold each portfolio in the out-of-sample period one month ahead, or $t+1(K=1)$. This strategy is referred to as $1-0-1(J-L-K)$. Industries with the lowest (highest) quintile returns in the previous month are allocated to the first (fifth) portfolio group. The zero-cost strategy is long group 5 and short group 1. Second, we compound returns from month $t-6(J=6)$ until $t-1$ $(L=1)$ and again hold each portfolio in the next month, which is referred to as strategy 6-1-1. As before, a long-short zero-investment portfolio is formed using groups 5 and 1, respectively. Third, and last, a 12-1-1 strategy is similarly implemented using industries with the lowest (highest) quintile returns for industry portfolio groups 1 and 5. The zero-cost strategies are updated at the beginning of each month. The profit performance for these industry momentum strategies during our sample period, June 1927 to February 2018, is summarized in Tables 1 and 2.

TABLE 1. Portfolio Sorts.

\begin{tabular}{|c|c|c|c|c|c|c|}
\hline Strategy & Group 1 (Loser) & Group 2 & Group 3 & Group 4 & Group 5 (Winner) & Winner-Loser \\
\hline \multicolumn{7}{|c|}{ Panel A. Predicted Returns } \\
\hline $1-0-1$ & 0.57 & 0.98 & 1.04 & 1.20 & 1.19 & $\begin{array}{l}0.62 * * * \\
(4.61)\end{array}$ \\
\hline $6-1-1$ & 0.65 & 1.01 & 1.01 & 1.09 & 1.22 & $\begin{array}{l}0.57 * * * \\
(3.52)\end{array}$ \\
\hline $12-1-1$ & 0.57 & 0.88 & 0.95 & 1.20 & 1.37 & $\begin{array}{l}0.80 * * * \\
(5.21)\end{array}$ \\
\hline \multicolumn{7}{|c|}{ Panel B. Cumulative Past Returns } \\
\hline $1-0-1$ & -5.08 & -1.14 & 0.80 & 2.78 & 7.06 & \\
\hline $6-1-1$ & -10.06 & -0.01 & 4.76 & 9.55 & 19.28 & \\
\hline $12-1-1$ & -12.63 & 2.72 & 9.89 & 16.85 & 31.02 & \\
\hline
\end{tabular}

Note: Panel A reports the average payoffs of five portfolio groups. Using 48 U.S. value-weighted industry portfolios, at the beginning of each month the industry portfolios are sorted in quintiles according to past performance. First, a strategy is calculated that considers returns from month $t-1(J=1)$ until $t(L=0)$, and holds the portfolios one month ahead, that is, until $t+1(K=1)$. This strategy is referred to as $1-0-1(J-L-K)$ and allocates industries with the lowest returns in the previous month to the first portfolio group, and industries with the highest returns in the last month to the fifth portfolio group. Then, a zero-cost strategy is implemented that is long on group 5 and short on group 1 . Second, a strategy is compounded that cumulates returns from month $t-6$ $(J=6)$ until $t-1(L=1)$, and holds the portfolios one month ahead, that is, until $t+1(K=1)$. This strategy is referred to as 6-1-1. This strategy allocates industries with the lowest cumulative returns in the formation period to the first portfolio group, and industries with the highest cumulative returns in the formation period to fifth portfolio group. The corresponding zero-cost strategy is then again long on group 5 and short on group 1. Finally, in a similar fashion, a 12-1-1 strategy is compounded. Panel B reports the corresponding average past return of the formation period. The data are downloaded from Kenneth French's website (http://mba.tuck.dartmouth.edu/ pages/faculty/ken.french/Data_Library/det_48_ind_port.html). The $t$-statistics are in parentheses. The sample period is from June 1927 to February 2018.

***Significant at the $1 \%$ level. 
TABLE 2. Descriptive Statistics.

\begin{tabular}{lrrr}
\hline Strategy & $1-0-1$ & $6-1-1$ & $12-1-1$ \\
\hline Mean & 0.62 & 0.57 & 0.80 \\
Median & 0.45 & 0.48 & 0.88 \\
Maximum & 22.31 & 19.03 & 17.45 \\
Minimum & -40.75 & -51.39 & -63.01 \\
Std. dev. & 4.39 & 4.14 & 5.03 \\
Skewness & -0.47 & -1.98 & -2.29 \\
Kurtosis & 13.31 & 29.39 & 30.03 \\
Jarque-Bera & $4,862.60$ & $32,310.84$ & $34,099.74$ \\
Probability & 0.00 & 0.00 & 0.00 \\
Sharpe ratio & 0.49 & 0.48 & 0.55 \\
\hline
\end{tabular}

Note: This table reports descriptive statistics for the strategies. The sample period is from June 1927 to February 2018.

Panel A of Table 1 shows that there is a linear spread when moving from portfolio group 1 to group 5 across strategies. The zero-cost strategies generate payoffs between 62 and 80 basis points per month, with highly significant $t$-statistics ranging from 3.52 to 5.21. The payoffs of our strategies are different from Moskowitz and Grinblatt (1999). The payoffs for the 1-0-1, 6-1-1, and 12-1-1 strategies reported in Table 3 of Moskowitz and Grinblatt are 105, 8, and 66 basis points per month, respectively, with corresponding $t$-statistics of 5.63, 0.41, and 3.11, indicating insignificance for the 6-1-1 strategy. However, Moskowitz and Grinblatt employ only 20 industrial portfolios, and their respective strategies are long the highest three past performing industries and short the lowest three. Possible explanations for the deviation between our results are that we employ 48 value-weighted industrial portfolios, quintile sorts, and approximately 20 years more data.

Our results challenge the weak form of the efficient market hypothesis in the sense that it should not be possible to earn substantial profits from historical price information (Fama 1970). Notice that cumulative past returns in the formation period increase linearly as we move across strategies from group 1 to group 5. These results are consistent with Grobys, Ruotsalainen, and Äijö (2018), who report spreads of 76 and 106 basis points for the 6-1-1 and 12-1-1 strategies, respectively.

TABLE 3. Correlation Matrix.

\begin{tabular}{lccc}
\hline Strategy & $1-0-1$ & $6-1-1$ & $12-1-1$ \\
\hline $1-0-1$ & 1 & & \\
$6-1-1$ & $0.20^{* * *}$ & & 1 \\
& $(6.88)$ & $0.67 * * *$ & $(29.54)$ \\
$12-1-1$ & $0.14 * * *$ & $(4.63)$ & \\
& & & \\
\hline
\end{tabular}

Note: This table reports the correlation matrix for the strategies. The $t$-statistics are in parentheses. The sample period is from June 1927 to February 2018.

*** Significant at the $1 \%$ level. 
The descriptive statistics in Table 2 indicate that skewness risk is lowest for the 1-0-1 strategy. This strategy has a Sharpe ratio equal to 0.49 (in annual terms), which is close to the 6-1-1 strategy Sharpe ratio equal to 0.48. Also, the minimum (maximum) monthly return of $-40.75 \%(22.31 \%)$ for the 1-0-1 strategy is clearly higher than the 12-1-1 strategy at $-63.01 \%(12.45 \%)$.

In contrast to Moskowitz and Grinblatt (1999), who explore 6-1-6, 6-1-12, 12-1-6, and 12-1-12 industry momentum strategies, we focus on a one-month holding period for the following reasons. First, we want to keep the time-series evolutions of all payoff series comparable. Second, we later investigate asset pricing implications of industry momentum strategies in the U.S. industrial universe. In this respect, we follow Fama and French (2018), who consider the monthly rebalanced stock price momentum strategy as a risk factor candidate for pricing U.S. stocks. Third, the literature analyzing risk-managing momentum strategies and momentum crashes focuses on monthly rebalanced strategies (Barroso and Santa-Clara 2015; Daniel and Moskowitz 2016; Moreira and Muir 2017). ${ }^{2}$

\section{Correlation Analysis, Risk Adjustments, and Control Variables}

We next explore the correlation structure between industry momentum strategies. The correlation matrix in Table 3 shows that the 1-0-1 strategy has a maximum correlation with other strategies of only 0.20 . By contrast, the correlation between the 6-1-1 and 12-1-1 strategies is relatively high at 0.67 with a $t$-statistic of 27.54 . In unreported results, principal component analyses of these strategies reveal that the first eigenvalue explains $58 \%$ of common variation, and the first two eigenvalues explain as much as $89 \%$. Although principal component analysis suggests that the first eigenvalue is dominant, with a standardized value greater than 1 at 1.75 , the second principal component is fairly large at 0.92 .

Results for risk-adjusting regressions are shown in Table 4 for the 1-0-1 zero-cost strategy. In model (1), the returns of the 1-0-1 strategy are regressed on the excess returns of the CRSP index. The strategy loads negatively and significantly on the market factor-a common characteristic of momentum strategies (see Grobys, Ruotsalainen, and Äijö 2018). The intercept increases from $0.62 \%$ per month to $0.68 \%$ per month after controlling for the market factor. Models (2) and (3) regress 1-0-1 strategy returns successively on 6-1-1 and 12-1-1 strategy returns, respectively. The resultant loadings are positive and statistically significant. In both models, the intercept decreases slightly from $0.62 \%$ to $0.52 \%$. Last, model (4) takes into account the Fama and French (1992, 1993) three-factor model as well as momentum spreads for the 6-1-1 and 12-1-1 strategies. Here, we see that the 1-0-1 strategy tends to be invested in large value stocks as the loadings against the size and value factors are negative and positive, respectively, and significant. Moreover, the long leg of the 1-0-1 zero-cost

\footnotetext{
${ }^{2}$ Because trading costs in U.S. stocks have declined dramatically, largely due to the decimalization of stock price quotes in April 2001, future studies are encouraged to explore the profitability of the 6-1-6, 6-1-12, 12-1-6, and 12-1-12 industry momentum strategies for the ex post 2001 period.
} 
TABLE 4. Risk Adjusting the 1-0-1 Strategy.

\begin{tabular}{|c|c|c|c|c|c|c|c|}
\hline Model & $\alpha$ & $C R S P$ & $S M B$ & $H M L$ & $6-1-1$ & $12-1-1$ & $R^{2}$ \\
\hline 1 & $\begin{array}{l}0.68 * * * \\
(5.15)\end{array}$ & $\begin{array}{l}-0.11 * * * \\
(-4.39)\end{array}$ & & & & & 0.02 \\
\hline 2 & $\begin{array}{l}0.52 * * * \\
(3.95)\end{array}$ & & & & $\begin{array}{l}0.22 * * * \\
(6.88)\end{array}$ & & 0.04 \\
\hline 3 & $\begin{array}{l}0.52 * * * \\
(3.88)\end{array}$ & & & & & $\begin{array}{l}0.12 * * * \\
(4.63)\end{array}$ & 0.02 \\
\hline 4 & $\begin{array}{l}0.56 * * * \\
(4.20)\end{array}$ & $\begin{array}{l}-0.05 * * \\
(-2.06)\end{array}$ & $\begin{array}{l}-0.16^{* * * *} \\
(-3.66)\end{array}$ & $\begin{array}{l}0.08 * * \\
(2.03)\end{array}$ & $\begin{array}{l}0.15^{* * *} * \\
(3.50)\end{array}$ & $\begin{array}{c}0.03 \\
(0.97)\end{array}$ & 0.06 \\
\hline
\end{tabular}

Note: This table reports the regressions for risk-adjusting the 1-0-1 strategy using different model specifications where $C R S P$ is the excess returns of the Center for Research in Security Prices index, SMB (small minus big) is the size factor, $H M L$ (high minus low) is the value factor, and 6-1-1 and 12-1-1 are the spreads of U.S. industry momentum portfolios based on recent and intermediate past performance, respectively. The $t$-statistics are in parentheses. The sample period is from June 1927 to February 2018.

$* * *$ Significant at the $1 \%$ level.

**Significant at the $5 \%$ level.

strategy tends to invest in past winner stocks as the loading on the 6-1-1 strategy is positive and significant. After simultaneously controlling for both strategies (i.e., 6-1-1 and 12-1-1), the loading on the 12-1-1 strategy becomes insignificant. ${ }^{3}$ Finally, the intercept term of the $1-0-1$ zero-cost strategy only slightly decreases after controlling for other risk factors and strategies.

\section{Risk Managing the Zero-Cost Strategy}

A number of studies have implemented risk-managed factor strategies. Seminal work by Barroso and Santa-Clara (2015) introduces risk-managed stock price momentum strategies by using a time-varying scaling factor to either leverage or deleverage the invested amount in the zero-cost portfolio. Their proposed scaling factor is based on the past six months of realized conditional volatility. Moreira and Muir (2017) explore the effects of risk managing the zero-cost factor spreads of the Fama and French $(2015,2017)$ five-factor model, the return on equity factor, the betting against the beta factor, the Hou, Xue, and Zhang (2015) investment factor, and the carry risk factor. They propose volatility-managed portfolios by scaling strategies' excess returns by the inverse of their conditional variance. This approach is similar to Barroso and Santa-Clara, but the estimation of conditional variance incorporates the observations of only the last 22 trading days, or about one month. Grobys, Ruotsalainen, and Äijö (2018) study the effects of risk managing the payoffs of industry momentum strategies. Using different time windows to estimate the time-varying scaling factor based on conditional volatility, in line with Moreira and Muir, their findings indicate that more recent volatility generates higher risk-managed payoffs than does the Barroso and Santa-Clara approach.

\footnotetext{
${ }^{3}$ This finding is consistent with the correlation matrix results in Table 3, wherein the correlation between the $1-0-1$ and $6-1-1$ strategies is stronger than that between the $1-0-1$ and $12-1-1$ strategies.
} 
Following these authors, we extend Moskowitz and Grinblatt's (1999) study and explore the effects of volatility scaling. We model a realized volatility estimator of the $1-0-1$ zero-cost strategy as follows:

$$
R V_{t}=\sum_{j=0}^{D_{m}} r_{d_{t-j}}^{2}
$$

where $R V_{t}$ is the realized variance in month $t, r_{d_{t-j}}^{2}$ are the squared daily returns over the trading days in the current month, and $D_{m}$ are the exact number of trading days in that month. The realized volatility of the 1-0-1 zero-cost strategy is plotted in Figure I. Visual inspection reveals that the realized volatility of this proposed strategy exhibits patterns similar to those of the 12-1-1 industry momentum strategy, as documented in Figure I in Grobys, Ruotsalainen, and Äijö (2018).

Following Barroso and Santa-Clara (2015), we also estimate a plain AR(1) model of the time series of realized variance. The intercept and first-order autocorrelation coefficient are estimated at 0.04 and 0.57 with $t$-statistics of 13.79 and 22.27, respectively, indicating statistical significance at any level. The $R^{2}$ is estimated at 0.32 . In unreported results, our findings are close to those of the estimated AR(1) model for the stock price momentum portfolio reported in Table 2 of Barroso and Santa-Clara.

Additionally, as first proposed by Barroso and Santa-Clara (2015) and Moreira and Muir (2017), we use a simple risk estimate of the 1-0-1 strategy to scale the exposure to constant risk over time. For each month $t$, the variance forecasts $\hat{\sigma}_{t}^{2}$ are computed from daily returns in the previous month. Let $\left\{r_{1-0-1, t}\right\}_{t=1}^{T}$ be the monthly returns of the 1-0-1 strategy and $\left\{r_{1-0-1, d}\right\}_{d=1}^{D},\left\{d_{t}\right\}_{t=1}^{T}$ be the daily returns and the time series of the last trading sessions of each month. Then the variance forecast is:

$$
\hat{\sigma}_{1-0-1, t}^{2}=T_{m} \sum_{j=0}^{D_{m}-1} r_{1-0-1, d_{t-1}}^{2} / T_{m},
$$

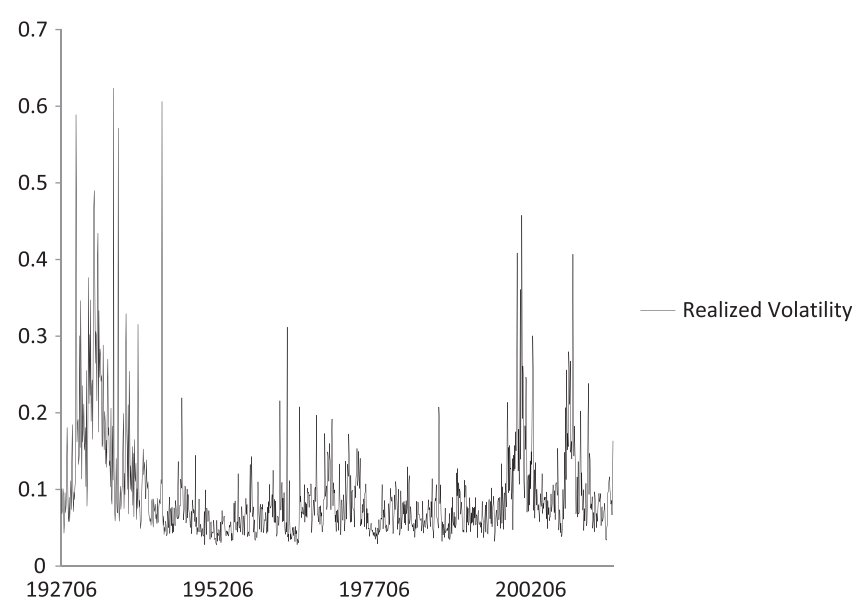

Figure I. Realized Volatility of the Short-Run Industry Momentum Portfolio. This figure plots the realized volatility of the 1-0-1 zero-cost industry momentum strategy. The sample period is from June 1927 to February 2018. 
where $r_{1-0-1, d_{t-1}}$ is the daily return of the 1-0-1 zero-cost strategy at time $d_{t-1}$, and $D_{m}$ is the number of trading days in the month before portfolio formation. Then the scaled payoffs are calculated as:

$$
r_{1-0-1^{*}, t}=\frac{\sigma_{\text {target }}}{\hat{\sigma}_{1-0-1, t}} r_{1-0-1, t},
$$

where $r_{1-0-1, t}$ is the strategy's unscaled payoff at time $t, r_{1-0-1^{*}, t}$ is the scaled or risk-managed momentum payoff, and $\sigma_{\text {target }}$ is a constant corresponding to the target level of volatility. As documented in Barroso and Santa-Clara (2015), scaling corresponds to weighting the long and short legs differently from one another conditional on time $t$. We follow Barroso and Santa-Clara (2015) and Grobys, Ruotsalainen, and Äijö (2018) in choosing $\sigma_{\text {target }}=12 \%$. As in Moreira and Muir (2017), both unconstrained and leverageconstrained volatility-managed payoffs are estimated. The authors consider their original strategies but cap the weights to be below 1 or 1.5 , which captures a tight no-leverage constraint and leverage of $50 \%$ (i.e., consistent with a standard margin requirements). The descriptive statistics of the three versions of volatility-managed portfolios are reported in Table 5.

Comparing the risk-managed payoffs in Table 5 with the corresponding payoffs of the plain strategy reported in Table 2, the Sharpe ratios are boosted for constrained strategies. The average payoff of the unconstrained risk-managed portfolio is $1.16 \%$ per month, which is $87 \%$ higher than the payoff of the plain strategy. Although Barroso and Santa-Clara (2015), Moreira and Muir (2017), and Grobys, Ruotsalainen, and Äijö (2018) report improvements in the skewness risks of various momentum strategies, the skewness risk of the 1-0-1 zero-cost strategy appears to be eliminated, as the skewness for all risk-managed strategies is positive, regardless of which constraint is taken into account. It is important to discern whether the increase in average payoff can be explained by exposures to other risk factors or by exposure to the plain strategy itself. For instance, Moreira and Muir document how the volatility-managed factors for market, momentum, profitability, return on equity,

TABLE 5. Descriptive Statistics for the Risk-Managed 1-0-1 Strategy.

\begin{tabular}{lrrr}
\hline Strategy & Unconstrained & Leverage 1.0 & Leverage 1.5 \\
\hline Mean & 1.16 & 0.64 & 0.90 \\
Median & 0.77 & 0.45 & 0.64 \\
Maximum & 43.75 & 21.50 & 32.25 \\
Minimum & -28.03 & -27.97 & -28.03 \\
Std. dev. & 6.38 & 3.81 & 5.07 \\
Skewness & 1.03 & 0.01 & 0.51 \\
Kurtosis & 9.74 & 9.91 & 9.03 \\
Jarque-Bera & $2,190.02$ & $2,105.49$ & $1,652.14$ \\
Probability & 0.00 & 0.00 & 0.00 \\
Sharpe ratio $^{\text {a }}$ & 0.63 & 0.58 & 0.61 \\
\hline
\end{tabular}

Note: This table reports descriptive statistics for the uncontrained risk-managed 1-0-1 strategy as well as constrained 1-0-1 strategies capping the weights at 1 to 1.5 , which corresponds to a no-leverage constraint and leverage of $50 \%$ (i.e., consistent with a standard margin requirement), respectively.

${ }^{\mathrm{a}}$ The Sharpe ratios are in annual terms. 
Hou, Xue, and Zhang (2015) investment, and betting against the beta all generate statistically significant intercepts after regressing the managed payoffs on the corresponding nonmanaged counterparts. Even after controlling for the nonmanaged counterpart, Grobys (2018) documents that the risk-managed 52-week high industry momentum strategy generates economically large risk-adjusted payoffs.

For these reasons, we follow previous authors and regress the risk-managed (unconstrained) 1-0-1 zero-cost strategy on the nonmanaged counterpart and control for the Fama and French (1993) three-factor model. The results in Table 6 show that between 33 and 36 basis points per month of the (unconstrained) risk-managed strategy remain unexplained after controlling for other factors. The $t$-statistics of the intercepts are highly significant between 3.31 and 3.71 .

These results are in line with Grobys (2018), who finds that 25 basis points per month of the 52-week high industry momentum strategy remains unexplained after controlling for other risk factors including the plain spread of the strategy itself. Additionally, consistent with Grobys's (2018) findings, the loading of the riskmanaged 1-0-1 strategy against the market factor is positive and significant. Finally, the constrained risk-managed strategies are employed and regressed on the plain 1-0-1 zero-cost strategy. In model (2), we control for the Fama and French $(2015,2017)$ five-factor model. Given the results in Tables A1 and A2 of the Appendix, our conclusions remain unchanged.

\section{Tail Risks and Optionality Effects}

Daniel and Moskowitz (2016) observe that written call options on the market exhibit patterns similar to momentum strategies in bear markets (i.e., nominal gains in market downturns but large losses in market upturns). Recent studies have investigated potential optionality effects of various momentum strategies. For example, Grobys (2015) confirms optionality effects for the 12-1-1 momentum strategy in the German stock market but not for stock price momentum based on recent performance. Grobys and Haga (2017) explore optionality effects for currency momentum strategies. They find significant optionality effects for

TABLE 6. Risk Adjusting the Risk-Managed 1-0-1 Strategy.

\begin{tabular}{ccccccc}
\hline Model & $\alpha$ & CRSP & $S M B$ & $H M L$ & $1-0-1$ & $R^{2}$ \\
\hline 1 & $0.36^{* * *}$ & & & & $1.25^{* * * *}$ & 0.75 \\
& $(3.71)$ & & & & $(56.78)$ & \\
2 & $0.33^{* * *}$ & $0.04^{* *}$ & $0.05^{*}$ & -0.03 & $1.26^{* * *}$ & 0.76 \\
& $(3.31)$ & $(2.10)$ & $(1.70)$ & $(-0.97)$ & $(56.53)$ & \\
\hline
\end{tabular}

Note: This table reports the results of regressing the risk-managed 1-0-1 strategy on the plain 1-0-1 strategy (model 1) and the Fama and French $(1992,1993)$ three-factor model controlling for the plain strategy (model 2). CRSP is the excess returns of the Center for Research in Security Prices index, SMB (small minus big) is the size factor, and $H M L$ (high minus low) is the value factor. The $t$-statistics are in parentheses. The sample period is from June 1927 to February 2018.

***Significant at the $1 \%$ level.

$* *$ Significant at the $5 \%$ level.

*Significant at the $10 \%$ level. 
currency momentum based on the cumulative return from 12 months to 1 month before the formation date. Like Grobys (2015), they do not find evidence for currency momentum based on recent performance. More recently, Grobys, Ruotsalainen, and Äijö (2018) and Grobys (2018) do not find support for optionality effects for industry momentum or 52-week high industry momentum, regardless of whether intermediate or recent past performance is considered.

Because the evidence for optionality effects with respect to momentum strategies is inconclusive, we extend Moskowitz and Grinblatt's (1999) study by examining optionality effects associated with the proposed 1-0-1 strategy for U.S. industry portfolios. Similar to Table 2 in Daniel and Moskowitz (2016), Table 7 reports the 15 most negative returns sorted by all strategies. Our results indicate that in only 2 (1) of 15 months do the worst negative returns of the 1-0-1 strategy coincide with the 6-1-1 (12-1-1) strategy. It is not surprising that the correlation of the tails of the return distributions is larger between the plain and risk-managed strategies. Also, comparing Panels A and D of Table 7, the worst returns of the strategies coincide with $40 \%$ of the observations. The lack of tail risk correlation between the 1-0-1 strategy and the 6-1-1 or 12-1-1 strategy suggests that tail risk (i.e., crash risk) in plain industry momentum strategies can be reduced simply by combining these two strategies. In contrast, comparing Panels $\mathrm{B}$ and $\mathrm{C}$, we see that the worst returns of the $6-1-1$ and $12-1-1$ strategies coincide more than $50 \%$ of the time ( 8 of 15 observations), which implies that combining these strategies is not as effective as combining any of the standard industry momentum strategies with the 1-0-1 strategy.

Next, we investigate whether the 1-0-1 strategy and its risk-managed counterpart exhibit any optionality effects. We use the following optionality regression based on Daniel and Moskowitz (2016, p. 228):

$$
\begin{aligned}
R_{t}^{1-0-1}= & \hat{\alpha}_{0}+\hat{\alpha}_{B} \times I_{B-1}+\hat{\beta}_{0} \times \tilde{R}_{m, t}^{e}+\hat{\beta}_{B} \times I_{B, t-1} \times \tilde{R}_{m, t}^{e} \\
& +\hat{\beta}_{B, U} \times I_{B, t-1} \times I_{U, t} \times \tilde{R}_{m, t}^{e}+u_{i, t},
\end{aligned}
$$

where $R_{t}^{1-0-1}$ is the $1-0-1$ zero-cost strategy at time $t, \hat{\alpha}_{0}$ is the risk-adjusted return of the unconditional model, $\hat{\beta}_{0}$ is the unconditional market sensitivity (e.g., beta), $\tilde{R}_{m, t}^{e}$ is the value-weighted market factor in excess returns (e.g., excess CRSP returns), and $I_{B, t-1}$ is an ex ante bear market indicator that equals 1 if the cumulative market return in the 24 months leading up to the start of month $t$ is negative, and 0 otherwise. The binary variable $I_{U, t}$ is a contemporaneous up-market indicator that equals 1 if the excess market return is greater than zero, and 0 otherwise.

If $\hat{\beta}_{B, U}$ has a nonzero value, we infer that the zero-cost portfolio exhibits option-like behavior relative to the market. To be more specific, a negative point estimate $\hat{\beta}_{B, U}$ implies that in bear markets, the zero-cost portfolio mimics a short call option on the market. The results of the regression models are reported in Table 8. Neither the plain 1-0-1 strategy nor the risk-managed counterpart demonstrates optionality effects (i.e., $\hat{\beta}_{B, U}$ are not statistically different from zero). This result confirms previous studies by Grobys (2015), Grobys and Haga (2017), and Grobys, Ruotsalainen, and Äijö (2018), who do not find support for momentum strategies based 
TABLE 7. Tail Risks.

\begin{tabular}{|c|c|c|c|c|c|}
\hline No. & Month & $1-0-1$ & $6-1-1$ & $12-1-1$ & RM 1-0-1 \\
\hline \multicolumn{6}{|c|}{ Panel A. Sorted by $1-0-1$ Strategy } \\
\hline 1 & $1933-05$ & -40.75 & -14.11 & 14.05 & -27.97 \\
\hline 2 & $1938-06$ & -23.41 & -8.05 & -18.08 & -28.03 \\
\hline 3 & $1935-10$ & -20.48 & 9.03 & -8.71 & -3.94 \\
\hline 4 & $2011-10$ & -16.66 & -8.62 & -4.13 & -21.37 \\
\hline 5 & $2002-12$ & -13.43 & 0.79 & 10.66 & -22.10 \\
\hline 6 & $2001-02$ & -12.76 & 14.33 & 16.39 & -7.96 \\
\hline 7 & $1931-01$ & -11.54 & -9.38 & -8.95 & -6.55 \\
\hline 8 & $2001-10$ & -10.94 & -3.39 & -2.97 & -5.45 \\
\hline 9 & $1933-07$ & -10.85 & -1.82 & -3.55 & -5.29 \\
\hline 10 & $1942-01$ & -10.66 & -4.07 & -7.75 & -20.39 \\
\hline 11 & $1938-04$ & -10.47 & -1.76 & 0.05 & -4.94 \\
\hline 12 & $2015-04$ & -10.14 & -4.83 & -7.83 & -15.02 \\
\hline 13 & 1934-08 & -9.95 & -6.21 & -7.75 & -7.27 \\
\hline 14 & $2000-09$ & -9.92 & 5.71 & -5.04 & -7.00 \\
\hline 15 & 1933-03 & -9.32 & -9.00 & 5.26 & -2.84 \\
\hline \multicolumn{6}{|c|}{ Panel B. Sorted by 6-1-1 Strategy } \\
\hline 1 & $1932-08$ & 22.31 & -51.39 & -63.01 & 5.76 \\
\hline 2 & 2009-04 & 11.71 & -23.19 & -34.75 & 6.90 \\
\hline 3 & 1934-11 & 0.92 & -21.83 & -3.02 & 0.41 \\
\hline 4 & 1939-09 & -7.53 & -20.49 & -16.84 & -2.86 \\
\hline 5 & 1934-01 & -3.40 & -16.64 & -9.96 & -2.55 \\
\hline 6 & $1933-05$ & -40.75 & -14.11 & 14.05 & -27.97 \\
\hline 7 & $1931-02$ & 11.08 & -13.37 & -19.49 & 8.79 \\
\hline 8 & $1932-07$ & 0.69 & -13.08 & -24.32 & 0.28 \\
\hline 9 & 1943-07 & 2.72 & -12.25 & -2.60 & 0.54 \\
\hline 10 & $2002-11$ & 8.72 & -12.08 & -16.64 & 4.19 \\
\hline 11 & 1943-08 & 13.51 & -11.34 & 2.85 & 21.22 \\
\hline 12 & $2002-10$ & -9.03 & -11.17 & -10.23 & -3.61 \\
\hline 13 & 1973-07 & -4.84 & -11.08 & -11.46 & -6.55 \\
\hline 14 & 1970-09 & 1.94 & -11.07 & -12.16 & 1.21 \\
\hline 15 & 1980-03 & -8.57 & -10.87 & -8.26 & -12.12 \\
\hline \multicolumn{6}{|c|}{ Panel C. Sorted by 12-1-1 Strategy } \\
\hline 1 & $1932-08$ & 22.31 & -51.39 & -63.01 & 5.76 \\
\hline 2 & 2009-04 & 11.71 & -23.19 & -34.75 & 6.90 \\
\hline 3 & $1932-07$ & 0.69 & -13.08 & -24.32 & 0.28 \\
\hline 4 & $1931-02$ & 11.08 & -13.37 & -19.49 & 8.79 \\
\hline 5 & $1938-06$ & -23.41 & -8.05 & -18.08 & -28.03 \\
\hline 6 & $1935-11$ & 9.37 & 8.69 & -17.84 & 8.75 \\
\hline 7 & $1975-01$ & -2.78 & -10.77 & -16.96 & -3.00 \\
\hline 8 & 1939-09 & -7.53 & -20.49 & -16.84 & -2.86 \\
\hline 9 & $2002-11$ & 8.72 & -12.08 & -16.64 & 4.19 \\
\hline 10 & $2001-01$ & -3.39 & -10.50 & -14.26 & -0.89 \\
\hline 11 & $2001-11$ & 3.78 & -6.49 & -12.76 & 6.44 \\
\hline 12 & 1970-09 & 1.94 & -11.07 & -12.16 & 1.21 \\
\hline 13 & 1973-07 & -4.84 & -11.08 & -11.46 & -6.55 \\
\hline 14 & 1939-03 & -3.48 & 7.40 & -11.09 & -3.55 \\
\hline 15 & 1930-01 & -3.22 & -7.52 & -10.42 & -2.08 \\
\hline
\end{tabular}

(Continued) 
TABLE 7. (Continued)

\begin{tabular}{|c|c|c|c|c|c|}
\hline No. & Month & $1-0-1$ & $6-1-1$ & $12-1-1$ & RM 1-0-1 \\
\hline \multicolumn{6}{|c|}{ Panel D. Sorted by RM 1-0-1 strategy } \\
\hline 1 & 1938-06 & -23.41 & -8.05 & -18.08 & -28.03 \\
\hline 2 & 1933-05 & -40.75 & -14.11 & 14.05 & -27.97 \\
\hline 3 & $2002-12$ & -13.43 & 0.79 & 10.66 & -22.10 \\
\hline 4 & $2011-10$ & -16.66 & -8.62 & -4.13 & -21.37 \\
\hline 5 & $1942-01$ & -10.66 & -4.07 & -7.75 & -20.39 \\
\hline 6 & 1986-10 & -7.66 & 1.47 & 5.96 & -18.22 \\
\hline 7 & 1950-08 & -6.23 & -0.14 & 0.25 & -18.19 \\
\hline 8 & $1950-05$ & -3.77 & 1.76 & 1.82 & -16.16 \\
\hline 9 & 2015-04 & -10.14 & -4.83 & -7.83 & -15.02 \\
\hline 10 & 1978-11 & -5.97 & 1.68 & 3.95 & -14.74 \\
\hline 11 & $2012-01$ & -8.69 & -6.58 & -8.37 & -13.77 \\
\hline 12 & $2012-08$ & -4.66 & -1.52 & -2.44 & -12.46 \\
\hline 13 & 1980-03 & -8.57 & -10.87 & -8.26 & -12.12 \\
\hline 14 & 1976-03 & -4.84 & -2.56 & -2.06 & -12.04 \\
\hline 15 & 1997-02 & -5.10 & -5.75 & -4.46 & -11.66 \\
\hline
\end{tabular}

Note: This table lists the 15 worst monthly returns to the $1-0-1,6-1-1,12-1-1$, and risk-managed (RM) 1-0-1 zero-cost strategies from June 1927 to February 2018. All numbers in the table are percentages. In every panel, the 15 worst payoffs are sorted with respect to one of the strategies.

TABLE 8. Optionality Regressions for the 1-0-1 Strategies.

\begin{tabular}{lccc}
\hline Coefficient & Variable & $1-0-1$ & RM $1-0-1$ \\
\hline$\hat{\alpha}_{0}$ & 1 & $0.88^{* * *}$ & $1.54^{* * *}$ \\
$\hat{\alpha}_{B}$ & $I_{B-1}$ & $(5.84)$ & $(6.93)$ \\
& & $-0.95 * *$ & $-1.14^{*}$ \\
$\hat{\beta}_{0}$ & $\tilde{R}_{m, t}^{e}$ & $(-2.17)$ & $(-1.77)$ \\
& & $-0.10^{* * *}$ & -0.08 \\
$\hat{\beta}_{B}$ & $I_{B, t-1} \cdot \tilde{R}_{m, t}^{e}$ & $(-2.84)$ & $(-1.47)$ \\
& & -0.03 & 0.04 \\
$\hat{\beta}_{B, U}$ & $I_{B, t-1} \times I_{U, t} \times \tilde{R}_{m, t}^{e}$ & $(-0.34)$ & $(0.39)$ \\
$R^{2}$ & & 0.01 & -0.13 \\
Log likelihood & & $(0.09)$ & $(-0.89)$ \\
\hline
\end{tabular}

Note: This table reports the results from the optionality regressions as in Daniel and Moskowitz (2016, p. 228) using the following specification:

$$
R_{t}^{1-0-1}=\hat{\alpha}_{0}+\hat{\alpha}_{B} \times I_{B-1}+\hat{\beta}_{0} \times \tilde{R}_{m, t}^{e}+\hat{\beta}_{B} \times I_{B, t-1} \times \tilde{R}_{m, t}^{e}+\hat{\beta}_{B, U} \times I_{B, t-1} \times I_{U, t} \times \tilde{R}_{m, t}^{e}+u_{i, t},
$$

where $R_{t}^{1-0-1}$ is the (risk-managed [RM]) 1-0-1 zero-cost strategy at time $t, \hat{\alpha}_{0}$ is the risk-adjusted return of the unconditional model, $\hat{\beta}_{0}$ is the unconditional market sensitivity (e.g., beta), $\tilde{R}_{m, t}^{e}$ is the value-weighted market factor in excess returns (e.g., excess Center for Research in Security Prices [CRSP] returns), and $I_{B, t-1}$ is an ex ante bear market indicator that equals 1 if the cumulative market return in the 24 months leading up to the start of month $t$ is negative, and 0 otherwise. The binary variable $I_{U, t}$ is a contemporaneous up-market indicator equal to 1 if the excess market return is greater than zero, and 0 otherwise. The $t$-statistics are in parentheses. The sample period is from June 1927 to February 2018.

***Significant at the $1 \%$ level.

**Significant at the 5\% level.

*Significant at the $10 \%$ level. 
on recent performance for stocks, currencies, and U.S. industry portfolios. Another interesting finding is that the risk-managed strategy generates average payoffs that are statistically uncorrelated with bear market states, the market factor, and the market factor conditional on bear market states. These results are in line with Grobys, Ruotsalainen, and Äijö, who find that the 6-1-1 and 12-1-1 strategies for U.S. industry portfolios lack correlations with these (conditional) factors. Finally, we use the constrained risk-managed strategies in the optionality regression model. Based on the results in Table A3, our main results remain unchanged.

\section{Cross-Sectional Asset Pricing Implications}

Various asset pricing models have been proposed in the finance literature. As cited in the Introduction, Lewellen, Nagel, and Shanken (2010) find that standard asset pricing factors do a poor job explaining the cross-section of industry returns. It is surprising that little effort has been directed at exploring potential drivers of the cross-section of industry portfolios that exhibit a different factor structure than stock portfolios sorted by (for instance) firm characteristics such as size and book-to-market ratio. Filling this gap in the literature, we explore the marginal usefulness of the proposed 1-0-1 strategy in the context of different stochastic discount factor model specifications. This novel aspect of our study extends Fama and French's (2018) study to the U.S. industry universe and complements Moskowitz and Grinblatt (1999), who do not explore potential asset pricing implication of momentum strategies. Using Cochrane's (2009) law of one price (LOP), the pricing equation is:

$$
\mathbf{0}=E\left[\zeta \boldsymbol{R}^{e}\right],
$$

where $\mathbf{0}$ is a vector of zeros, $\zeta$ is the pricing kernel function, and $\boldsymbol{R}^{e}$ is the vector of expected excess returns for 48 value-weighted industries. As suggested by Burnside (2007), the factor matrices are demeaned. We employ the recently proposed Fama and French $(2015,2017)$ five-factor model based on Novy-Marx's (2013) valuation model. This model is composed of market (excess returns of the CRSP index), size (small minus big $[S M B]$ ), value (high minus low book-to-market ratio $[H M L]$ ), profitability (robust minus weak profitability $[R M W]$ ), and investment (conservative minus aggressive investing $[C M A])$ factors. The kernel function is given by:

$$
\begin{aligned}
\zeta_{1, t+1}= & 1-b_{1}\left(C R S P_{t+1}^{e x}-E\left[C R S P_{t+1}^{e x}\right]\right)-b_{2}\left(S M B_{t+1}-E\left[S M B_{t+1}\right]\right) \\
& -b_{3}\left(H M L_{t+1}-E\left[H M L_{t+1}\right]\right)-b_{4}\left(R M W_{t+1}-E\left[R M W_{t+1}\right]\right) \\
& -b_{5}\left(C M A_{t+1}-E\left[C M A_{t+1}\right]\right) .
\end{aligned}
$$

We estimate this stochastic discount factor model using the GMM estimation method with optimal weighting matrix (Hansen 1982). Unlike the analyses reported earlier, the sample period starts in September 1969 because of data availability for some industry portfolios.

As shown in the first row of Table 9, the market factor clearly matters for pricing the cross-section of U.S. industry returns, as the $t$-statistic of 5.33 is highly significant at 
TABLE 9. Estimated Stochastic Discount Factor Models Using 48 U.S. Industry Portfolios as Test Assets.

\begin{tabular}{|c|c|c|c|c|c|c|c|c|c|}
\hline $1-0-1$ & $6-1-1$ & $12-1-1$ & $\begin{array}{c}\mathrm{RM} \\
1-0-1\end{array}$ & $C R S P$ & $S M B$ & $H M L$ & $R M W$ & $C M A$ & Hansen \\
\hline \multirow{9}{*}{$\begin{array}{l}0.07 * * \\
(1.97)\end{array}$} & \multirow{9}{*}{$\begin{array}{c}0.04 \\
(1.18)\end{array}$} & \multirow{9}{*}{$\begin{array}{c}0.04 \\
(1.62)\end{array}$} & & $\begin{array}{l}0.07 * * * \\
(5.33)\end{array}$ & $\begin{array}{l}-0.06 * * * \\
(-3.11)\end{array}$ & $\begin{array}{l}-0.04 \\
(-1.03)\end{array}$ & $\begin{array}{l}0.07 * * \\
(2.17)\end{array}$ & $\begin{array}{c}0.09 \\
(1.19)\end{array}$ & 52.53 \\
\hline & & & & $0.08 * * *$ & $-0.06 * * *$ & -0.03 & $0.07 * *$ & 0.09 & 46.21 \\
\hline & & & & $(6.47)$ & $(-2.75)$ & $(-0.79)$ & (2.08) & (1.19) & \\
\hline & & & & $0.08 * * *$ & $-0.06^{* * *}$ & -0.03 & 0.04 & 0.08 & 52.77 \\
\hline & & & & $(5.31)$ & $(-2.59)$ & $(-0.69)$ & (1.34) & (1.07) & \\
\hline & & & & $0.07 * * *$ & $-0.06^{* * *}$ & -0.00 & $0.07 * *$ & 0.04 & 49.14 \\
\hline & & & & $(5.28)$ & $(-2.62)$ & $(-0.01)$ & $(2.15)$ & $(0.50)$ & \\
\hline & & & $0.08 * * *$ & $0.08 * * *$ & $-0.05 * *$ & -0.03 & $0.06^{*}$ & 0.09 & 41.25 \\
\hline & & & $(2.62)$ & $(5.40)$ & $(-2.19)$ & $(-0.67)$ & (1.81) & $(1.25)$ & \\
\hline
\end{tabular}

Note: This table reports the estimation results of stochastic discount factor models in equations (5), (6). The excess returns of 48 value-weighted U.S. industry portfolios are employed as test assets. The pricing kernel function $\zeta_{t+1}$ as specified by Burnside (2007) is:

$$
\zeta_{t+1}=1-\sum_{j=1}^{K} b_{j}\left(f_{j, t+1}^{e x}-E\left[f_{j, t+1}^{e x}\right]\right),
$$

where $f_{j, t+1}^{e x}$ denotes the (portfolio-based) risk factor in excess form, and $b_{j}$ denotes the cross-sectional sensitivity for $j=1, \ldots, K$. The table displays the estimators $\hat{b}_{1}, \ldots, \hat{b}_{K}$. Following Cochrane (2009), the stochastic discount factor models are estimated using Hansen's (1982) generalized method of moments (GMM) estimators. CRSP is the excess returns of the Center for Research in Security Prices index, $S M B$ (small minus big) is the size factor, $H M L$ (high minus low) is the value factor, $R M W$ is the profit factor, and $C M A$ is the investment factor. RM is the risk-managed strategy. The $t$-statistics are in parentheses. The sample period is from September 1969 to February 2018.

$* * *$ Significant at the $1 \%$ level.

**Significant at the $5 \%$ level.

*Significant at the $10 \%$ level.

any level. The size and profitability factors exhibit significance at the 5\% level or lower, but the value and investment factors do not. Consistent with Lewellen, Nagel, and Shanken (2010), the five-factor model has difficulty pricing value-weighted U.S. industry assets.

We next augment the stochastic discount factor model in equation (6) with different industry momentum $(M O M)$ spreads as well as the proposed 1-0-1 strategy:

$$
\begin{aligned}
\zeta_{1, t+1}= & 1-b_{1}\left(M O M_{t+1}^{(J / L / K)}-E\left[M O M_{t+1}^{(J / L / K)}\right]\right)-b_{2}\left(C R S P_{t+1}^{e x}-E\left[C R S P_{t+1}^{e x}\right]\right) \\
& -b_{3}\left(S M B_{t+1}-E\left[S M B_{t+1}\right]\right)-b_{4}\left(H M L_{t+1}-E\left[H M L_{t+1}\right]\right) \\
& -b_{5}\left(R M W_{t+1}-E\left[R M W_{t+1}\right]\right)-b_{6}\left(C M A_{t+1}-E\left[C M A_{t+1}\right]\right) .
\end{aligned}
$$

The results in rows $2-5$ of Table 9 reveal that the traditional $6-1-1$ and 12-1-1 industry momentum strategies are not marginally useful for pricing the cross-section of U.S. industry portfolios. These findings are surprising in view of earlier research highlighting the importance of the momentum factor for pricing (international) equities (Carhart 1997; NovyMarx 2013; Asness, Moskowitz, and Pedersen 2013; Fama and French 2018). By contrast, the spread of the 1-0-1 strategy appears to be an important factor for pricing industry 
portfolios. The plain strategy exhibits statistical significance at the 5\% level $(t=1.97)$, and the risk-managed counterpart is significant at the $1 \%$ level $(t=2.62)$.

Notice that as we move from the standard Fama and French (2015) fivefactor model to the stochastic discount factor model accounting for the plain 1-0-1 strategy, the Hansen test result falls from 52.53 to 46.21. The difference in $p$-values is 0.15 , which means that adding the plain $1-0-1$ strategy considerably reduces pricing errors. The reduction in pricing errors is improved further by adding the risk-managed 1-0-1 strategy to the Fama and French (2015) fivefactor model. The drop from 52.53 to 41.25 in the value of the Hansen test statistic corresponds to a difference in $p$-values of 0.35 . These results imply that the spread of the risk-managed 1-0-1 strategy is an important factor for pricing the crosssection of U.S. industry portfolios.

\section{Robustness Checks}

Are the Payoffs Sample Specific? Schwert (2003) observes that many of the well-known anomalies in the finance literature are not present in different sample periods. In a recent paper, Cotter and McGeever (2018) study the persistence over time of nine well-known equity market anomalies and find strong evidence of diminished statistical significance for most anomalies over time. Hence, we split our sample period from June 1927 to February 2018 into two subsamples of equal length: June 1927 to December 1972 and January 1973 to February 2018. The regression results using the 1-0-1 strategy for these subsamples are reported in Tables 10 and 11. In sum, we find that the economic magnitude of the spread does not diminish in the second subsample.

One could argue that trading costs in U.S. stocks have declined dramatically, largely due to the decimalization of stock price quotes in April 2001. In light of this

TABLE 10. Risk-Adjustments for the 1-0-1 Strategy in the Subsample Period from June 1927 to December 1972.

\begin{tabular}{|c|c|c|c|c|c|c|c|}
\hline Model & $\alpha$ & $C R S P$ & $S M B$ & $H M L$ & $6-1-1$ & $12-1-1$ & $R^{2}$ \\
\hline 1 & $\begin{array}{l}0.73 * * * \\
(3.47)\end{array}$ & $\begin{array}{l}-0.09 * * * \\
(-2.68)\end{array}$ & & & & & 0.01 \\
\hline 2 & $\begin{array}{l}0.50 * * \\
(2.39)\end{array}$ & & & & $\begin{array}{l}0.24 * * * \\
(5.58)\end{array}$ & & 0.05 \\
\hline 3 & $\begin{array}{l}0.56 * * * \\
(2.64) 0\end{array}$ & & & & & $\begin{array}{l}0.11 * * * \\
(2.92)\end{array}$ & 0.02 \\
\hline 4 & $\begin{array}{l}0.55^{* * *} \\
(2.62)\end{array}$ & $\begin{array}{l}-0.06 \\
(-1.47)\end{array}$ & $\begin{array}{l}-0.22 * * * \\
(-3.15)\end{array}$ & $\begin{array}{l}0.17 * * * \\
(2.76)\end{array}$ & $\begin{array}{l}0.22 * * * \\
(3.64)\end{array}$ & $\begin{array}{l}-0.01 \\
(-0.16)\end{array}$ & 0.08 \\
\hline
\end{tabular}

Note: This table reports the regressions for risk adjusting the 1-0-1 strategy using different model specifications, where $C R S P$ is the excess returns of the Center for Research in Security Prices index, SMB (small minus big) is the size factor, $H M L$ (high minus low) is the value factor, and 6-1-1 and 12-1-1 are the corresponding spreads of U.S. industry momentum portfolios based on recent or intermediate past performance, respectively. The $t$-statistics are in parentheses. The sample period is from June 1927 to December 1972.

$* * *$ Significant at the $1 \%$ level.

**Significant at the $5 \%$ level. 
TABLE 11. Risk Adjustments for the 1-0-1 Strategy in the Subsample from January 1973 to February 2018.

\begin{tabular}{cccccccc}
\hline Model & $\alpha$ & CRSP & SMB & $H M L$ & $6-1-1$ & $12-1-1$ & $R^{2}$ \\
\hline 1 & $0.65^{* * *}$ & $-0.14^{* * *}$ & & & & & 0.03 \\
& $(3.94)$ & $(-3.84)$ & & & & & $0.18^{* * *}$ \\
2 & $0.54^{* *}$ & & & $(3.60)$ & & $0.13^{* * *}$ & 0.03 \\
& $(3.30)$ & & & & & $(3.80)$ & \\
3 & $0.48^{* * *}$ & & & & & $0.10^{* *}$ & 0.06 \\
& $(2.91)$ & & & & & & \\
4 & $0.59^{* * *}$ & $-0.11^{* * *}$ & $-0.13^{* *}$ & -0.03 & 0.04 & $(2.10)$ & \\
& $(3.50)$ & $(-2.72)$ & $(-2.28)$ & $(-0.55)$ & $(0.51)$ & \\
\hline
\end{tabular}

Note: This table reports the regressions for risk-adjusting the 1-0-1 strategy using different model specifications, where $C R S P$ is the excess returns of the Center for Research in Security Prices index, SMB (small minus big) is the size factor, $H M L$ (high minus low) is the value factor, and 6-1-1 and 12-1-1 are the corresponding spreads of U.S. industry momentum portfolios based on recent or intermediate past performance, respectively. The $t$-statistics are in parentheses. The sample period is from January 1973 to February 2018.

$* * *$ Significant at the $1 \%$ level.

**Significant at the $5 \%$ level.

decrease in transactions costs, it is likely much easier to directly exploit the $1-0-1$ strategy that requires frequent trading, and one would expect a priori that the profitability of the strategy is lower than what is was previously. Therefore, we also investigate the May 2001 to February 2018 period separately. Given this sample period, the average returns for these strategies are 19, 9, and 34 basis points per month with corresponding $t$-statistics of $0.64,0.37$, and 0.84 , respectively, indicating that none of these strategies generates significant payoffs over this subsample period. In Figure II, we plot the timeseries evolutions of the cumulative returns of the $1-0-1,6-1-1$, and 12-1-1 strategies over the whole sample period. Although it is perhaps challenging to investigate reasonably the period before World War II, we observe from Figure II that the profitability of these strategies seems to be different across time. For instance, the cumulative returns of the 12-1-1 strategy exhibit a linear trend in the ex post World War II period, whereas the cumulative returns of the 6-1-1 strategy experience a structural break. Specifically, visual inspection of Figure II shows that from the early 70s onward, the cumulative returns of the 6-1-1 strategy do not exhibit such a linear trend anymore. This is an interesting finding because it confirms Novy-Marx (2012), who argues that the 6-1-1 strategy implemented among U.S. stocks does not generate any significant payoffs in either the 1969-1989 or 1990-2010 period. However, Figure II also shows that the cumulative returns of the 1-0-1 strategy start to exhibit a linear trend later than the other strategies, that is, from the early 60 s onward. This trend then seemingly ebbs away in the mid-90s, but continues again in the recovery of the dot.com bubble burst when stock prices worldwide begin to rise again. In the ex post financial crisis period, the cumulative returns of the 1-0-1 strategy do not indicate profitability of this strategy anymore. Future research is encouraged to investigate the time-varying properties of industrial momentum strategies in more detail.

Can the 1-1-0 Strategy Be a Risk Factor? Motivated by Cochrane's (2009) LOP, Charoenrook and Conrad (2008) propose a new test to assess whether factormimicking equity portfolios are priced risk factors. The authors argue that a 


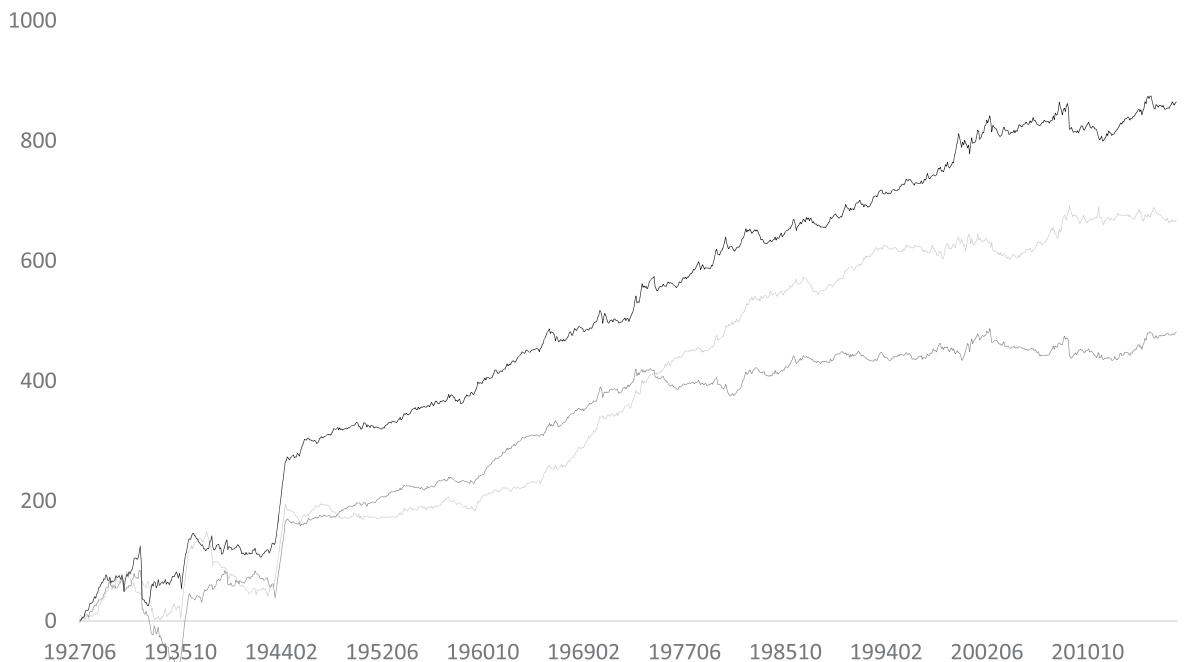

$-200$

1-0-1 - 6-1-1 - 12-1-1

Figure II. Cumulative Returns of Value-Weighted Industry Momentum Portfolios. This figure plots the cumulative payoffs of the 1-0-1, 6-1-1, and 12-1-1 industry momentum strategies using valueweighted U.S. industrial portfolios for the June 1927 to February 2018 sample period.

linear relation between the factor-mimicking portfolio's conditional mean and its conditional variance must exist if a suggested factor-mimicking portfolio is to be considered a risk factor. Moreover, the sign of the relation must be the same as the sign of the factor-mimicking portfolio's (sample) average. Testing the size, value, and momentum factors in the U.S. equity market in the 1963-2003 sample period, the size and value factors meet these necessary conditions, whereas stock price momentum does not.

Although the results of the stochastic discount factor models in the previous section show that the spread of the risk-managed 1-0-1 strategy in particular is useful for pricing industry portfolios, a question remains as to whether there is any theoretical motivation to employ this strategy as a risk factor. Here, we extend Moskowitz and Grinblatt's (1999) study by investigating this issue in detail, and similar to Charoenrook and Conrad (2008) and Grobys and Haga (2016), we employ the following generalized autoregressive conditional heteroskedasticity-in-mean models (GARCH-in-mean models):

$$
\begin{gathered}
r_{i, t+1}^{1-0-1}=\alpha_{i}+\gamma_{i} \sigma_{i, t+1}+\varepsilon_{i, t+1}, \\
r_{i, t+1}^{1-0-1}=\alpha_{i}+\gamma_{i} \sigma_{i, t+1}+\sum_{k=1}^{K} \beta_{k} f_{k}+\varepsilon_{i, t+1}, \\
r_{i, t+1}^{1-0-1}=\alpha_{i}+\gamma_{i} \sigma_{i, t+1}^{2}+\varepsilon_{i, t+1},
\end{gathered}
$$


TABLE 12. Estimated GARCH-in-Mean Models Employing the Plain 1-0-1 Strategy.

\begin{tabular}{|c|c|c|c|c|c|c|c|}
\hline \multicolumn{5}{|c|}{ Mean Equation } & \multicolumn{3}{|c|}{ Variance Equation } \\
\hline Constant & Volatility & $C R S P$ & $S M B$ & $H M L$ & Constant & $\mathrm{ARCH}$ & GARCH \\
\hline \multicolumn{8}{|c|}{ Panel A. Estimates Using Variance in the Mean Equation } \\
\hline $0.32 * *$ & 0.01 & & & & $0.31 * * *$ & $0.15 * * *$ & $0.85 * * *$ \\
\hline$(2.32)$ & (1.33) & & & & $(3.94)$ & $(8.62)$ & $(56.26)$ \\
\hline $0.45 * * *$ & 0.01 & $-0.13 * * *$ & & & $0.41 * * *$ & $0.17 * * *$ & $0.82 * * *$ \\
\hline$(3.22)$ & (1.34) & $(-8.92)$ & & & (3.97) & (7.36) & $(40.44)$ \\
\hline $0.48 * * *$ & 0.01 & $-0.11 * * *$ & $-0.15 * * *$ & -0.09 & $0.46 * * *$ & $0.20 * * *$ & $0.79 * * *$ \\
\hline$(3.42)$ & $(1.30)$ & $(-7.12)$ & $(-5.92)$ & $(-3.53)$ & $(3.96)$ & $(7.41)$ & (34.27) \\
\hline \multicolumn{8}{|c|}{ Panel B. Estimates Using Volatility in the Mean Equation } \\
\hline 0.06 & 0.13 & & & & $0.31 * * *$ & $0.15 * * *$ & $0.85^{* * *}$ \\
\hline$(0.24)$ & (1.58) & & & & $(3.95)$ & $(8.55)$ & $(56.10)$ \\
\hline 0.21 & 0.12 & $-0.13 * * *$ & & & $0.40 * * *$ & $0.17 * * *$ & $0.82 * * *$ \\
\hline (1.57) & (1.57) & $(-8.17)$ & & & $(4.02)$ & (7.36) & $(40.69)$ \\
\hline 0.22 & 0.13 & -0.11 & $-0.15 * * *$ & -0.09 & $0.46 * * *$ & $0.20 * * *$ & $0.79 * * *$ \\
\hline (0.79) & (1.53) & $(-7.10)$ & $(-5.74)$ & $(-3.50)$ & $(4.02)$ & $(7.41)$ & $(34.58)$ \\
\hline
\end{tabular}

Note: This table reports the estimation results for different generalized autoregressive conditional heteroskedasticity-in-means (GARCH-in-mean) models. Panel A reports the results for employing conditional variance in the conditional mean equations:

$$
r_{t+1}^{1-0-1}=\alpha+\gamma \sigma_{t+1}^{2}+\varepsilon_{t+1}
$$

or

$$
r_{t+1}^{1-0-1}=\alpha+\gamma \sigma_{t+1}^{2}+\sum_{k=1}^{K} \beta_{k} f_{k}+\varepsilon_{t+1},
$$

where $r_{t+1}^{1-0-1}$ is the log-return of $1-0-1$ zero-cost strategy at time $t, \sigma_{t+1}$ and $\sigma_{t+1}^{2}$ are conditional volatility or conditional variance at time $t, f_{1}, \ldots, f_{K}$ are control variables, and $\varepsilon_{t+1}$ is the corresponding white-noise process. As control variables, the Fama and French $(1992,1993)$ risk factors are taken into account. The variance is modeled as:

$$
\sigma_{t+1}^{2}=\delta_{0}+\delta_{1} \varepsilon_{t}^{2}+\delta_{3} \sigma_{t}^{2}
$$

where $\sigma_{t+1}^{2}$ is the conditional variance at time $t$ for the portfolio. Panel B reports the results of employing the conditional variance in the conditional mean equations:

$$
r_{t+1}^{1-0-1}=\alpha+\gamma \sigma_{t+1}+\varepsilon_{t+1}
$$

or

$$
r_{t+1}^{1-0-1}=\alpha+\gamma \sigma_{t+1}+\sum_{k=1}^{K} \beta_{k} f_{k}+\varepsilon_{t+1} .
$$

CRSP is the excess returns of the Center for Research in Security Prices index, SMB (small minus big) is the size factor, and $H M L$ (high minus low) is the value factor. The $t$-statistics are in parentheses. The sample period is from June 1927 to February 2018.

***Significant at the $1 \%$ level.

**Significant at the 5\% level. 
TABLE 13. Estimated GARCH-in-Mean Models Employing the Risk-Managed 1-0-1 Strategy.

\begin{tabular}{|c|c|c|c|c|c|c|c|}
\hline \multicolumn{5}{|c|}{ Mean Equation } & \multicolumn{3}{|c|}{ Variance Equation } \\
\hline Constant & Volatility & $C R S P$ & $S M B$ & $H M L$ & Constant & $\mathrm{ARCH}$ & GARCH \\
\hline \multicolumn{8}{|c|}{ Panel A. Estimates Using Variance in the Mean Equation } \\
\hline $\begin{array}{l}-0.90 \\
(-1.23)\end{array}$ & $\begin{array}{l}0.05^{* *} \\
(2.22)\end{array}$ & & & & $\begin{array}{l}11.77 * * * \\
(5.90)\end{array}$ & $\begin{array}{l}0.15 * * * \\
(5.87)\end{array}$ & $\begin{array}{l}0.51 * * * \\
(6.90)\end{array}$ \\
\hline-0.79 & $0.05^{* *}$ & $-0.14 * * *$ & & & $11.55^{* * *}$ & $0.16^{* * *}$ & $0.50 * * *$ \\
\hline$(-1.14)$ & $(2.24)$ & $(-7.01)$ & & & $(6.05)$ & (5.74) & $(7.01)$ \\
\hline-0.61 & $0.05 * *$ & $-0.07 * * *$ & $-0.23 * * *$ & -0.06 & $9.67 * * *$ & $0.16^{* * *}$ & $0.55 * * *$ \\
\hline$(-0.93)$ & (2.19) & $(-2.56)$ & $(-5.41)$ & $(-1.41)$ & $(6.19)$ & (6.21) & $(9.38)$ \\
\hline
\end{tabular}

Panel B. Estimates Using Volatility in the Mean Equation

\begin{tabular}{|c|c|c|c|c|c|c|c|}
\hline $\begin{array}{l}-3.09 * \\
(-1.78)\end{array}$ & $\begin{array}{l}0.69 * * \\
(2.18)\end{array}$ & & & & $\begin{array}{l}12.09 * * * \\
(5.75)\end{array}$ & $\begin{array}{l}0.15 * * * \\
(5.93)\end{array}$ & $\begin{array}{l}0.50 * * * \\
(6.43)\end{array}$ \\
\hline$-2.86^{*}$ & $0.66^{* *}$ & $-0.13 * * *$ & & & $11.87^{* * *}$ & $0.17 * * *$ & $0.48^{* * *}$ \\
\hline$(-1.74)$ & (2.19) & $(-6.94)$ & & & $(5.96)$ & $(5.83)$ & $(6.57)$ \\
\hline $\begin{array}{l}-2.39 \\
(-1.55)\end{array}$ & $\begin{array}{l}0.59 * * \\
(2.09)\end{array}$ & $\begin{array}{l}-0.07 * * \\
(-2.56)\end{array}$ & $\begin{array}{l}-0.23 * * * \\
(-5.34)\end{array}$ & $\begin{array}{l}-0.58 \\
(-1.41)\end{array}$ & $\begin{array}{l}10.19 * * * \\
(6.02)\end{array}$ & $\begin{array}{l}0.16^{* * * *} \\
(6.30)\end{array}$ & $\begin{array}{l}0.53 * * * \\
(8.39)\end{array}$ \\
\hline
\end{tabular}

Note: This table reports the estimation results of different generalized autoregressive conditional heteroskedasticity-in-means (GARCH-in-mean) models. Panel A reports the results of employing conditional variance in the conditional mean equations:

$$
r_{t+1}^{1-0-1}=\alpha+\gamma \sigma_{t+1}^{2}+\varepsilon_{t+1}
$$

or

$$
r_{t+1}^{1-0-1}=\alpha+\gamma \sigma_{t+1}^{2}+\sum_{k=1}^{K} \beta_{k} f_{k}+\varepsilon_{t+1}
$$

where $r_{t+1}^{1-0-1}$ is the log-return of the risk-managed $1-0-1$ zero-cost strategy at time $t, \sigma_{i, t+1}$ and $\sigma_{i, t+1}^{2}$ are conditional volatility or conditional variance at time $t, f_{1}, \ldots, f_{K}$ are control variables, and $\varepsilon_{t+1}$ is the corresponding white-noise process. As control variables, the Fama and French $(1992,1993)$ risk factors are taken into account. The variance is modeled as:

$$
\sigma_{t+1}^{2}=\delta_{0}+\delta_{1} \varepsilon_{t}^{2}+\delta_{3} \sigma_{t}^{2}
$$

where $\sigma_{i, t+1}^{2}$ is conditional variance at time $t$ for the portfolio. Panel B reports the results of employing the conditional variance in the conditional mean equations:

$$
r_{t+1}^{1-0-1}=\alpha+\gamma \sigma_{t+1}+\varepsilon_{t+1},
$$

or

$$
r_{t+1}^{1-0-1}=\alpha+\gamma \sigma_{t+1}+\sum_{k=1}^{K} \beta_{k} f_{k}+\varepsilon_{t+1}
$$

CRSP is the excess returns of the Center for Research in Security Prices index, SMB (small minus big) is the size factor, and $H M L$ (high minus low) is the value factor. The $t$-statistics are in parentheses. The sample period is from June 1927 to February 2018.

***Significant at the $1 \%$ level.

**Significant at the $5 \%$ level.

*Significant at the $10 \%$ level. 


$$
r_{i, t+1}^{1-0-1}=\alpha_{i}+\gamma_{i} \sigma_{i, t+1}^{2}+\sum_{k=1}^{K} \beta_{k} f_{k}+\varepsilon_{i, t+1},
$$

where $r_{i, t+1}^{1-0-1}$ is the log-return of zero-cost strategy $i$ at time $t ; \sigma_{i, t+1}$ and $\sigma_{i, t+1}^{2}$ are the conditional volatility and conditional variance of zero-cost strategy $i$ at time $t+1$, respectively; $f_{1}, \ldots, f_{K}$ are control variables; and $\varepsilon_{i, t+1}$ is the corresponding white-noise process. Moreover, strategy $i$ can be either the plain 1-0-1 strategy or its risk-managed counterpart. The variance for models (8)-(11) is given by:

$$
\sigma_{i, t+1}^{2}=\delta_{0, i}+\delta_{1, i} \varepsilon_{i, t}^{2}+\delta_{3, i} \sigma_{i, t}^{2}
$$

where $\sigma_{i, t+1}^{2}$ is the conditional variance at time $t+1$ for portfolio $i$. Because the conditional variance can be considered a function of the volatility and vice versa, both models are investigated. The results are reported in Tables 12 and 13. Regardless of model specification, our findings in Table 12 suggest that the plain 1-0-1 strategy does not meet the necessary conditions. The loadings against the conditional variance (conditional volatility) are not statistically different from zero, and the intercepts are positive. Regardless of model specification in Table 13, the risk-managed 1-0-1 strategy exhibits a positive relation to its conditional variance (volatility). The loadings against conditional variance (volatility) are statistically significant at the 5\% level for different model specifications, and corresponding intercepts are not statistically different from zero at the $5 \%$ significance level. Hence, the risk-managed 1-0-1 strategy implemented using U.S. industries meets the necessary conditions for being considered a risk factor. ${ }^{4}$

\section{Conclusion}

In this article, we investigate the asset pricing implications of first-order autocorrelation in momentum strategies based on U.S. industry portfolios. We employ a portfolio approach common to asset pricing research. Our findings indicate that first-order autocorrelation plays an important role in spanning the cross-section of U.S. industry returns. Using quintile sorts, the spread between industries with the highest previous-month returns and those with the lowest previous-month returns (dubbed a $1-0-1$ strategy) is economically large and statistically significant at any level. Our results challenge the efficient market hypothesis that posits that all information is reflected in current asset prices with no ability to garner profits via historical asset price information. We also find that the correlations between the $1-0-1$ strategy and traditional industry momentum strategies defined as 6-1-1 and 12-1-1 are low, and that controlling for traditional industry momentum does not diminish the significance of the 1-0-1 strategy or its economic magnitude.

\footnotetext{
${ }^{4}$ An increasing number of approaches have been proposed to identify risk factors (see, e.g., Pukthuanthong, Roll, and Subrahmanyam 2019 and citations therein). It is beyond the scope of our article to take into account all of these approaches.
} 
Risk managing the 1-0-1 strategy boosts its Sharpe ratio. Stochastic discount factor models indicate that the spread of the risk-managed strategy matters for pricing the cross-section of U.S. industry portfolios. In this regard, further analyses reveal that the risk-managed spread is a risk factor that meets necessary conditions. Future research should explore whether this strategy plays a role in pricing equity portfolios sorted by firm and other characteristics. Other possible areas of future study include potential links between the risk-managed 1-0-1 strategy payoffs and macroeconomic fundamentals, and whether other risk-managed strategies proposed in the literature satisfy necessary conditions for accepting factor-mimicking portfolios as risk factors.

\section{Appendix}

TABLE A1. Risk Adjusting the Risk-Managed 1-0-1 Strategy with Leverage Constrained at 1.0.

\begin{tabular}{lcccccc}
\hline Model & $\alpha$ & CRSP & SMB & $H M L$ & $1-0-1$ & $R^{2}$ \\
\hline 1 & $0.12^{* * *}$ & & & & $0.83 * * *$ & 0.92 \\
& $(3.53)$ & & & & $(111.84)$ & $0.83 * * *$ \\
2 & $0.11 * * *$ & 0.01 & -0.00 & $-0.02 * *$ & 0.92 \\
& $(3.49)$ & $(1.56)$ & $(-0.11)$ & $(-1.98)$ & $(110.12)$ & \\
\hline
\end{tabular}

Note: This table reports the results of regressing the constrained risk-managed $1-0-1$ strategy on the plain 1-0-1 strategy (model 1) and the Fama and French $(1992,1993)$ three-factor model controlling for the plain strategy (model 2). The constraint strategy caps the weights at below 1, which captures a tight no-leverage constraint. $C R S P$ is the excess returns of the Center for Research in Security Prices index, small minus big $(S M B)$ is the size factor, and high minus low $(H M L)$ is the value factor. The $t$-statistics are in parentheses. The sample period is from June 1927 to February 2018.

*** Significant at the $1 \%$ level.

$* *$ Significant at the $5 \%$ level.

TABLE A2. Risk Adjusting the Risk-Managed 1-0-1 Strategy with Leverage Constrained at 1.5.

\begin{tabular}{lcccccc}
\hline Model & $\alpha$ & CRSP & SMB & HML & $1-0-1$ & $R^{2}$ \\
\hline 1 & $0.22^{* * *}$ & & & $1.06^{* * *}$ & 0.85 \\
& $(3.67)$ & & & & $(78.71)$ & \\
2 & $0.21^{* * *}$ & $0.03^{* *}$ & 0.02 & -0.02 & $1.06^{* * *}$ & 0.86 \\
& $(3.33)$ & $(2.28)$ & $(0.86)$ & $(-0.87)$ & $(77.92)$ & \\
\hline
\end{tabular}

Note: This table reports the results of regressing the constrained risk-managed $1-0-1$ strategy on the plain 1-0-1 strategy (model 1) and the Fama and French $(1992,1993)$ three-factor model controlling for the plain strategy (model 2). The constraint strategy caps the weights at below 1.5, which captures a leverage of 50\% (i.e., consistent with a standard margin requirement). CRSP is the excess returns of the Center for Research in Security Prices index, small minus big $(S M B)$ is the size factor, and high minus low $(H M L)$ is the value factor. The $t$ statistics are in parentheses. The sample period is from June 1927 to February 2018.

$* * *$ Significant at the $1 \%$ level.

**Significant at the $5 \%$ level. 
TABLE A3. Optionality Regressions Risk-Managed Portfolios with Leverage Constraints.

\begin{tabular}{lccc}
\hline Coefficient & Variable & Leverage 1.0 & Leverage 1.5 \\
\hline$\hat{\alpha}_{0}$ & 1 & $0.89^{* * *}$ & $1.22^{* * *}$ \\
$\hat{\alpha}_{B}$ & $I_{B-1}$ & $(6.71)$ & $(6.90)$ \\
$\hat{\beta}_{0}$ & $-0.63^{*}$ & $-0.91^{*}$ \\
$\hat{\beta}_{B}$ & $\tilde{R}_{m, t}^{e}$ & $(-1.65)$ & $(-1.79)$ \\
$\hat{\beta}_{B, U}$ & $I_{B, t-1} \bullet \tilde{R}_{m, t}^{e}$ & $-0.06^{* *}$ & -0.07 \\
$R^{2}$ & & $(-2.10)$ & $(-1.64)$ \\
Log likelihood & $I_{B, t-1} \bullet I_{U, t} \bullet \tilde{R}_{m, t}^{e}$ & 0.02 & 0.03 \\
& & $(0.28)$ & $(0.30)$ \\
& & -0.10 & -0.12 \\
\end{tabular}

Note: This table reports the results from the optionality regressions as in Daniel and Moskowitz (2016, p. 228) using the following specification:

$$
R_{i, t}^{1-0-1}=\hat{\alpha}_{0}+\hat{\alpha}_{B} \cdot I_{B-1}+\hat{\beta}_{0} \cdot \tilde{R}_{m, t}^{e}+\hat{\beta}_{B} \cdot I_{B, t-1} \cdot \tilde{R}_{m, t}^{e}+\hat{\beta}_{B, U} \cdot I_{B, t-1} \cdot I_{U, t} \cdot \tilde{R}_{m, t}^{e}+u_{i, t}
$$

where $R_{t i,}^{1-0-1}$ is the constrained $1-0-1$ zero-cost strategy at time $t, \hat{\alpha}_{0}$ is the risk-adjusted return of the unconditional model, $\hat{\beta}_{0}$ is the unconditional market sensitivity (e.g., beta), $\tilde{R}_{m, t}^{e}$ is the value-weighted market factor in excess returns (e.g., excess Center for Research in Security Pries [CRSP] returns), and $I_{B, t-1}$ is an ex ante bear market indicator that equals 1 if the cumulative market return in the 24 months leading up to the start of month $t$ is negative, and 0 otherwise. The index $i$ denotes the constrained strategy that either caps the weights at 1 or 1.5 , which captures a tight no-leverage constraint and leverage of $50 \%$ (i.e., consistent with a standard margin requirement), respectively. The binary variable $I_{U, t}$ is a contemporaneous up-market indicator that equals 1 if the excess market return is greater than zero, and 0 otherwise. The $t$-statistics are in parentheses. The sample period is from June 1927 to February 2018.

$* * *$ Significant at the $1 \%$ level.

**Significant at the $5 \%$ level.

* Significant at the $10 \%$ level.

\section{References}

Asness, C. S., T. J. Moskowitz, and L. H. Pedersen, 2013, Value and momentum everywhere, Journal of Finance 68, 929-85.

Barroso, P., and P. Santa-Clara, 2015, Momentum has its moments, Journal of Financial Economics 116, 111-20.

Burnside, C., 2007, Empirical asset pricing and statistical power in the presence of weak risk factors, NBER Working Paper No. 13357.

Carhart, M. M., 1997, On persistence in mutual fund performance, Journal of Finance 52, 57-82.

Charoenrook, A., and J. Conrad, 2008, Identifying risk-based factors, Working Paper, Vanderbilt University and University of North Carolina.

Chordia, T., and A. Shivakumar, 2002, Momentum, business cycle and time-varying expected returns, Journal of Finance 57, 985-1019.

Cochrane, J., 2009, Asset Pricing (Rev. ed.) (Princeton University Press, Princeton, NJ).

Cotter, J., and N. McGeever, 2018, Are equity market anomalies disappearing? Evidence from the U.K., Working Paper, University College Dublin.

Daniel, K., and T. Moskowitz, 2016, Momentum crashes, Journal of Financial Economics 122, 221-47.

Fama, E. F., 1970, Efficient capital market: A review of theory and empirical work, Journal of Finance 25, 383-417. 
Fama, E. F., and K. R. French, 1992, The cross-section of expected stock returns, Journal of Finance 47, 427-65.

Fama, E. F., and K. R. French, 1993, Common risk factors in the returns on stocks and bonds, Journal of Financial Economics 33, 3-56.

Fama, E. F., and K. R. French, 2015, A five-factor asset pricing model, Journal of Financial Economics 116, 1-22.

Fama, E. F., and K. R. French, 2017, International tests of a five-factor asset pricing model, Journal of Financial Economics 123, 441-63.

Fama, E. F., and K. R. French, 2018, Choosing factors, Journal of Financial Economics 128, $234-52$.

George, T., and C. Y. Hwang, 2004, The 52-week high and momentum investing, Journal of Finance 59, 2145-76.

Grobys, K., 2015, Another look at momentum crashes: Momentum in the European Monetary Union, Applied Economics 48, 1759-66.

Grobys, K., 2018, Risk-managed 52-week high industry momentum, momentum crashes, and hedging macroeconomic risk, Quantitative Finance 18, 1233-47.

Grobys, K., and J. Haga, 2016, Identifying portfolio-based systematic risk factors in equity markets, Finance Research Letters 17, 88-92.

Grobys, K., and J. Haga, 2017, Are momentum crashes pervasive regardless of strategy? Evidence from the foreign exchange market, Applied Economics Letters 24, 1499-1503.

Grobys, K., J. Ruotsalainen, and J. Äijö, 2018, Risk-managed industry momentum and momentum crashes, Quantitative Finance 18, 1715-33.

Grundy, B. D., and J. S. Martin, 2001, Understanding the nature of the risks and the source of the rewards to momentum investing, Review of Financial Studies 14, 29-78.

Hansen, L., 1982, Large sample properties of generalized method of moments estimators, Econometrica 50, 1029-54.

Hou, K., C. Xue, and L. Zhang, 2015, Digesting anomalies: An investment approach, Review of Financial Studies 28, 650-705.

Jegadeesh, N., and S. Titman, 1993, Returns to buying winners and selling losers: Implications for stock market efficiency, Journal of Finance 48, 35-91.

Lewellen, J., 2002, Momentum and autocorrelation in stock returns, Review of Financial Studies 15, 533-64.

Lewellen, J., S. Nagel, and J. Shanken, 2010, A skeptical appraisal of asset pricing tests, Journal of Financial Economics 96, 175-94.

Lintner, J., 1965, The valuation of risk assets and the selection of risky investments in stock portfolios and capital budgets, Review of Economics and Statistics 47, 13-37.

Moreira, A., and T. Muir, 2017, Volatility-managed portfolios, Journal of Finance 72, 1611-44.

Moskowitz, T. J., and M. Grinblatt, 1999, Do industries explain momentum? Journal of Finance 54, 1249-90.

Mossin, J., 1966, Equilibrium in a capital asset market, Econometrica 34, 768-83.

Novy-Marx, R., 2012, Is momentum really momentum? Journal of Financial Economics 103, 429-53.

Novy-Marx, R., 2013, The other side of value: The gross profitability premium, Journal of Financial Economics 108, 1-28.

Pan, S., K. Liano, and G.-C. Huang, 2004, Momentum strategies and autocorrelations in stock returns, Journal of Empirical Finance 11, 185-202.

Plessis, J. P. D., and W. G. Hallerbach, 2016, Volatility weighting applied to momentum strategies, Journal of Alternative Investments 19, 40-58.

Pukthuanthong, K., R. Roll, and A. Subrahmanyam, 2019, A protocol for factor identification, Review of Financial Studies 32, 1573-1607.

Schwert, G. W., 2003, Anomalies and market efficiency, in G. M. Constantinides, M. Harris, and R. Stulz eds., Handbook of the Economics of Finance (Elsevier Science, Amsterdam).

Sharpe, W. F., 1964. Capital asset prices: A theory of market equilibrium under conditions of risk, Journal of Finance 19, 425-42.

Su, D., 2011, An empirical analysis of industry momentum in Chinese stock markets, Emerging Markets Finance and Trade 47, 4-27.

Swinkels, L., 2002, International industry momentum, Journal of Asset Management 3, 124-41.

Treynor, J. L., 1961, Market value, time, and risk, Unpublished manuscript.

Treynor, J. L., 1962, Toward a theory of market value of risky assets, Unpublished manuscript.

Xiuqing, J., and C. I. Giannikos, 2010, The profitability, seasonality and source of industry momentum, Applied Financial Economics 20, 1337-49. 